\title{
Pollution, Energy Consumption and Economic Growth: evidence from India, China and Brazil
}

\author{
${ }^{1}$ Mohsen Mehrara, ${ }^{*}$ Hossein Amiri ${ }^{2}$ \\ 1 University of Tehran, Iran \\ 2Economy, University of Allmeh Tabata'I, Iran \\ *hossienamiri@gmail.com
}

\begin{abstract}
This paper examines the relationships between the energy consumption, GDP growth and emission, using Panel Smooth Transition Regression (PSTR) model for BRIC countries over the period 1960 -2006. Our results reveal that environmental quality in these countries has increasingly suffered from high energy consumption. Moreover, rapid economic growth and international trade in energy intensive goods have progressively increased energy consumption. This suggests that excessively high economic growth is a curse for environmental quality and energy conservation policies to reduce unnecessary wastage of energy should be kicked off for energy-dependent BRIC countries.
\end{abstract}

Key words: $\mathrm{CO}_{2}$ Emission, energy consumption, industrialization and economic growth

\section{Introduction}

Rapid economic growth which has been created through industrialization in developing economies such as India, China and Brazil has had a negative effect on the quality of the environment. Developing economies have created serve pollution problems by emission of some poisonous gases like $\mathrm{CO}_{2}$. Higher emission of such gases in these countries is due to higher energy consumption. More population growth rate, rapid industrialization and industrial trade reflecting a high economic growth are some effective variables on high energy consumption. Economic growth is enormously high in China and India. The higher growth levels have placed these two economies in the different League of Nations altogether. China and India together, contributes 30\% of the whole GDP in the world in 2002-2003¹. In 2006 China has experienced a growth rate over 10 percent, while India has done in the rate of 9 percent and Brazil in the rate of 4\%. Moreover, in 2011 the growth rates for India, China and Brazil have been 7.7, 2.3 and1.3 respectively ${ }^{2}$.

The growth rate of GDP of India between 1950 and 1980 was around 3\% and annual growth of per capita income was just $1.5 \%$. For a country like India which is the second over- populated country in the world, the growth rate is insufficient to impact on the development. Some initiation was taken up during the 1980 s by the government of India to set things right. Though they were half hearted, it improved the per capita income growth to $3.0 \%$ as poverty levels fell from over $45 \%$ to $35 \%$ by the end of 1980 . Thus, India realized that only strong economic growth rate could increase the per capita income levels of the people which in turn help in bringing down the poverty levels and improve the socioeconomic conditions of the poor. This further encouraged the government to make some serious corrections in its economic policies. The government implemented Structural Adjustment Program (SAP) in 1991. This SAP had concentrated on the economic growth which led to decrease of poverty level and improving the Indian people's life standards. By beginning the SAP, economy experienced the 7\% growth rate for three consecutive years. Having followed up the trend, India economy has come to higher economic growth rates at the beginning of 2000, so that the growth rate in 2006 has been over 10\% (Trading Economics.com, India Central Statistical Orga). Similarly about China, Maddison (1998) sum up in his researches that China has been able to increase their investments growth rates considerably in the last three decades which led to increase in GDP by over $8 \%$ and helped the country reach the growth of per capita income by over $6 \%$. Chinese higher economic growth rates were appreciated by the World Bank in 2006 which stated in its report that because of the high economic growth rate, China was able to bring $75 \%$ of its poor population out of the poverty.

About Brazil, the economic growth rate is below 5\% in 2006, though this country experienced the economic growth rate of over $8 \%$ in the 1970 s. Due to serious economic crisis especially problems like

\footnotetext{
1. Word bank (2004)

2. Trading Economics.com
} 
foreign loans, economic growth rate reached $3 \%$ in the early $1980 \mathrm{~s}, 1.5 \%$ in $1990 \mathrm{~s}, 2.5 \%$ in early 2000 and 1.7\% in 2006 (Trading Economics.com, IBGE). On the other hand, some experts have stated other cases, in opposition to rapid economic growth rates which have been shown in such countries (Juan P. Chousa, Artur Tamazian \& Krishna Chaitanya Vadlamannati, 2008). They believed that rapid economic growth and developing economic activities create enormous expenses such as environmental expenses, greenhouse effect, global warming and destroying jungles. As well as the above mentioned matters, environmental destruction causes higher health expenditure for the poor. According to the UN report, $20 \%$ of the poorest population of the world takes this extra expense as the result of environmental destruction.

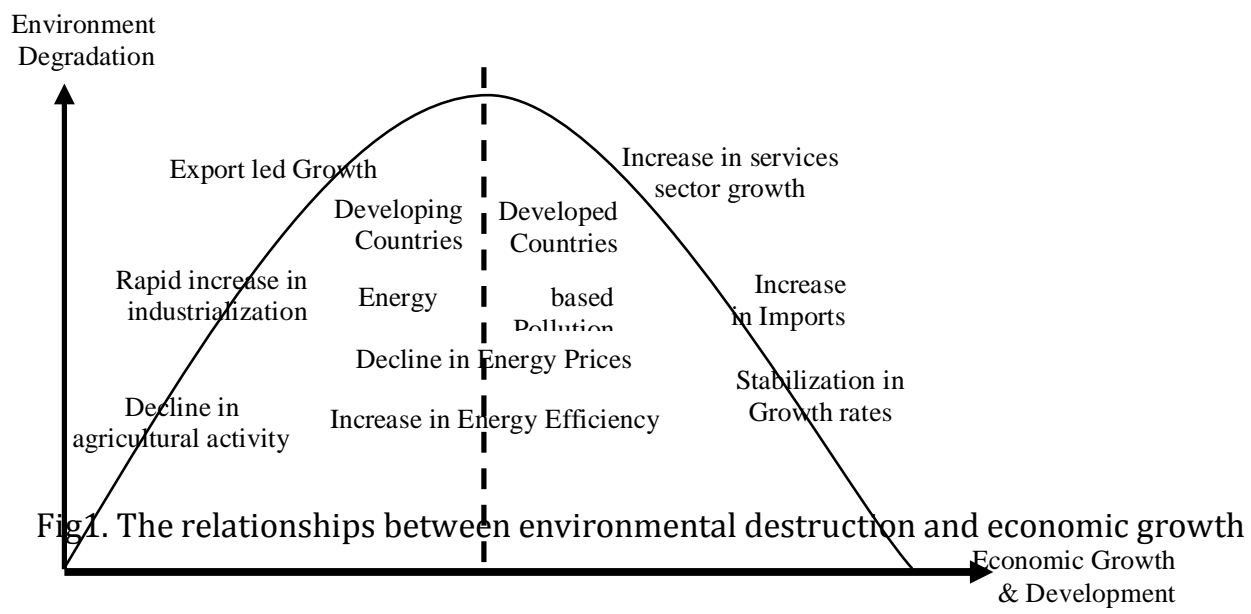

The important fact about all three countries; India, China and Brazil is that all these countries are in a level of rapid industrialization. This level is the result of high economic growth, which leads to changing economic activities structure, more industrial export, less industrial import, mush industrial activities and production and high rate of growth in population. The case has been shown in the best way by Environmental Kuznets Curve (EKC). The relationship between the environmental destruction and economic growth is clarified in figure 1. According to Kuznets Curve theory, pollution level increases by the development level but when the income is above the amount of threshold, the pollution level decreases. Therefore the relationships between the pollution level and income are shown like a reversed U curve. This theory was first brought to discussion by Grossman and Krueger in 1992 and then again and restated by them again in 1995 .

As it is shown in the figure 1, the upward movement of the curve captures the developing countries that move from agricultural based economy to industrialization phase. In the next phase, the income per capita exceeds the threshold one and the downward movement of the curve starts with a shift of economy structure towards services, increase in imports of industrial goods and stabilization of growth rates All three countries, India, China and Brazil are said to be in the first phase where the structural changes from farming to industrialization have been sharply happened. Farming share of GDP for India decreased remarkably from above $80 \%$ in the 1950 s to about $25 \%$ in 2007 and in China it decreased from about $60 \%$ to $25 \%$. Industry share of GDP increased from about $20 \%$ to over $50 \%$ in the same period. About Brazil its traditional strong kept in industry and its share of industry increased from about $38 \%$ of GDP in the 1970 s to above $40 \%$ in 2007 . At the same period, also energy consumption levels and $\mathrm{CO}_{2}$ emission regretfully increased in these countries.

In this paper, we examine the relationships between the energy consumption and GDP growth from one hand and $\mathrm{CO}_{2}$ emission and energy consumption from the other hand by the use of Panel Smooth Transition Regression (PSTR) model for a panel of BRIC countries over the period 1960-2006. In this approach, changes in the values of parameters between countries and their change over time are modeled continuously. The rest of paper is organized as follows. Section 2 presents the literature review. Section 3 outlines the econometric models and data sources. We report the empirical estimates and results in section 4 . Section 5 concludes. 


\section{Literature Review}

In the economic literature, the relationships between per capita gross domestic product and environmental destruction which is in the form of a reversed $U$, is known as Environmental Kuznets Curve (EKC). The EKC literature is abundant in studies that test for linear, as well as nonlinear relationships between per capita gross domestic product and $\mathrm{CO}_{2}$ emissions. These studies treat environmental degradation measure(s) as the dependent variable(s) and product as the independent variable and provide mixed results. Hill and Magnani (2002), Dinda (2004), Copeland and Taylor (2004), and Stern (2004) provide a good review of this extensive EKC research. The literature points out several problems in the empirical studies. The criticisms include econometric issues. Studies about EKC literature have implied the existence of a unique relationship between per capita income and the pollution is weak and fragile and have proposed a more exact interpretation. At the first levels of growth, the pollution is increasing with a decreasing rate then it reaches the peak and finally decreases by an increasing rate. The peak of this curve is called "dematerialization".

After the peak of the curve, the economy will reduce the consumption of material and energy in production process (Martines- Zarzoso \& Bengochea- Morancho, 2003). As a matter of fact, the message of this hypothesis is clear and it's that economic growth is both the cause of pollution and its cure. The result of studies have been more or less different on the basis of data selection (time series or panel data), using other variables as well as income and pollution, model estimation methods, the period of time and the kind of the countries (developing or developed). Mielnik and Goldemberg (1999) and Opschoor (1997) introduced three factors including important structural changes in economy, improving efficiency in energy consumption and reforming the energy consumption pattern to explain EKC hypothesis. The hypothesis of the Environmental Kuznets Curve (EKC) was brought forth for discussion in the early 1990s and after above mentioned events. Kuznets phrase is used here due to similarity with main hypothesis of Kuznets curve in which the hump shape relationships between income distribution and economic growth are examined.

From the first studies about the Environmental Kuznets Curve, we can point to Grossman and Krueger (1992) that by examining 52 cities in 32 countries, they confirmed the hump shape curve whose peak was in the range of $\$ 4772$ to $\$ 5965$. Shafik and Bandyopadhyay's (1992) study, which was done for 153 countries from 1961 to 1986, found no evidence to confirm EKC. Holtz- Eakin and Selden's papers (1995), for 108 countries over the period of 1951-1986, and Sengupta (1996), for 16 developed countries and a few developing countries, confirmed EKC hypothesis. Tucker (1995), also with annual data over the period of 1971-1991 and for 108 countries reached the same conclusion. The studies about EKC hypothesis got fast, entering other variables in model to test this hypothesis. For example Cole et al (1997) entered technology, population and trade into the model for 7 areas in the world over the period of 1960-1992, and reached the hump shape. But Agras and Chapman (1999) using income, $\mathrm{CO}_{2}$ emission and the volume of trade of 34 countries over the period of 1971-1989 didn't come to hump shape for EKC. EKC hypothesis in Panayoton's job (2000) was confirmed for 17 developed countries with income data, $\mathrm{CO}_{2}$ emission, trade volume, capital stock and population over the period of 1870-1994. Roca and Alcantra (2001) by cointegration method, over the period of 1973-1996 in Spain, entering energy price in model, couldn't confirm EKC hypothesis.

Bengochia, Moranko et al (2001) with annual data over the period of 1980-1995 in some countries in the European Union reached a hump shaped relationship. Heerink, Mulatu and Bullet (2001) with use of inequality variable reached the hump shaped relationship on data of 153 countries. Martiner- Zorzoso et al (2002) with data over the period of 1975-1998 for 22 countries, which are members of OECD, reached an $\mathrm{N}$ shape relationship. Neumayer (2002) reached a bell shaped curve by examining the climate conditions, fossil fuel resources, available renewable resources and transportation equipments as explanatory variables for 148 countries. Friedl and Getzner (2003) reached an N shape curve by Australia annual data over the period of 1960-1999 and considering the ratio of import to GDP and the ratio of the service production to GDP using cointegration approach. Lantz and Feng (2006) using statistics from 5 areas in Canada over the period of 1970-2000 and considering the population and technology as explanatory variables concluded that there is no relationships between per capita GDP and $\mathrm{CO}_{2}$, but $\mathrm{CO}_{2}$ has a hump shaped relationship with population and technology. Galeotti et al (2006) by the use of RIO1

1.United Nation Framework Convention on Climate Change, Reports on International Organizations (RIO) 
data over the period of 1960-1998 and cointegration approach concluded hump shape curve for OECD countries.

Some Studies about EKC used non- parametric methods that among them, the most important studies are as follows: Taskin and Zaim (2000) reached the hump shape through Kernel non-parametric method for data of counties with low and high income. Azomahu and Vanphy (2001), by the use of the same method, for 100 countries reached the hump shaped relationships. But Baiocchi and Di Falco's (2001) study by using non-parametric method for 160 countries didn't confirm the EKC hypothesis.

Lee and Chang (2007a) and Huang et al. (2008), in effect, assume a nonlinear relationship between energy consumption and GDP. Moon and Sonn (1996) employed an endogenous growth model to infer that the economic growth rate rises initially with productive energy expenditure but subsequently declines. In other words, there is an inverse Unshaped nonlinear relationship between energy consumption and economic growth as was evidenced by their empirical results from the yearly data extending from 1968 to 1989 in Korea. Lee and Chang (2007b) used the level of total energy consumption as a threshold variable to investigate the existence of a nonlinear relationship under the one sector and two-sector growth models. The empirical result from the 1955-2003 annual data in Taiwan indicates that there is an inverse U-shaped relationship between energy consumption growth and economic growth. That is, the relationship between energy consumption and economic growth indicated above is nonlinear and the traditional linear model is no longer appropriate.

\section{Econometric Model}

This paper examines the relationships between the energy consumption and GDP growth from one hand and $\mathrm{CO}_{2}$ emission and energy consumption from the other hand by the use of a Panel Smooth Transition Regression (PSTR) model for a panel of BRIC countries (Brazil, India and China) over the period 19602006. The problem of cross-section heterogeneous and energy demand model instability is a serious problem. Pesaran and Smith (1995) and Hsiao (2003) stated that ignoring this issue may lead to bias. Also Hensen and King (1996) stated that heterogeneity in cross-country data will lead to an estimate more than unity for income elasticity. It is difficult to solve both of these problems contemporaneously. A simple solution for solving the heterogeneity is specifying a Panel Smooth Threshold Regression (PSTR) that recently has been developed by Fok et al. (2004), Gonzalez et al. (2005), Colletaz and Hurlin (2005) and Fouquau et al. (2008). In this approach, change in parameters among countries and also change in parameters over time are modeled continuously. Thus, this approach is proper for removing heterogeneity among countries and the changing coefficients in the energy demand model.

To allow for nonlinearities we use a transition regression model based on panel data (PSTR). Smooth transition regression model is a non-linear time series model that can be considered as a more developed species of regression models with varying coefficients that has been introduced by Bacon and Wats (1971). For first time in time series literature, Grenger and Terasvirta (1993) has described and suggested STR smooth transition model in their studies. PSTR model may be specified into either exponential smooth transition model (ESTR) or logistic smooth transition (LSTR) as following:

$\mathrm{Y}_{\mathrm{t}}=\alpha+\varphi \mathrm{z}_{\mathrm{t}}+\theta \mathrm{z}_{\mathrm{t}} \mathrm{F}\left(\mathrm{q}_{\mathrm{t}}\right)+\varepsilon_{\mathrm{t}}=\alpha+\left(\varphi+\theta \mathrm{F}\left(\mathrm{q}_{\mathrm{t}}\right)\right) \mathrm{z}_{\mathrm{t}}+\varepsilon_{\mathrm{t}}$

LSTR: $F\left(\mathrm{q}_{\mathrm{t}}\right)=1 /\left(\left(1+\exp \left\{-\gamma\left(\mathrm{q}_{\mathrm{t}}-\mathrm{c}\right)\right\}\right)\right)$

ESTR: $F\left(q_{t}\right)=1-1 /\left(\left(\exp \left\{-\gamma\left(q_{t}-c\right)^{\wedge} 2\right\}\right)\right)$

Where $Y_{t}$ is dependant variable, $\alpha$ is intercept and $z_{t}$ is vector of explanatory variables. In this specification, the coefficients of explanatory variables are not constant and are functions of $\mathrm{q}_{\mathrm{t}}$, namely, transition or threshold variable. $\mathrm{F}\left(\mathrm{q}_{\mathrm{t}}\right)$ is transition function, $\mathrm{c}$ is threshold parameter and $\gamma>0$ is smooth parameter. $\mathrm{q}_{\mathrm{t}}$ can be variables within the model $\left(\mathrm{z}_{\mathrm{t}}\right)$, their lags, or ones out of model. The transition function is between zero and one. This function is mainly dependent on transition variable ( $\mathrm{q}_{\mathrm{it}}$ ), threshold parameter (c) and the smooth parameter $(\gamma)$. The above specification indicates that model can be interpreted as a linear model with stochastic time-varying coefficients. For LSTR model, coefficients of $\varphi+\theta \mathrm{F}\left(\mathrm{q}_{\mathrm{t}}\right)$ change monotonically as function of $\mathrm{q}$ from $\varphi$ to $\varphi+\theta$ (when qt moves from $\infty$ to $+\infty$ ). But at ESTR function, coefficients change symmetrical about middle point c from $\varphi$ to $\varphi+\theta$ (when qt moves from c toward $\pm \infty$ ). Thus LSTR model is able to model symmetrical behavior of variables. For example, this model is proper where boom periods show different behaviors from depression ones and transition from one regime to another regime takes place smoothly. On the other hand, the ESTR model is appropriate in situations in which the local dynamic behavior of the process is similar at both large and small values of 
qt and different in the middle. When smooth parameter is $\gamma=0$, the transition function will be $F(q t)=1$ and thus STR model will change into a linear model. On the other hand, when $\gamma \rightarrow \infty$, the LSTR model will change into regression model with 2 discrete regimes. At ESTR model, if $\gamma \rightarrow \infty$ in fact it leads to a linear model.

In this paper we use LSTR approach for modeling the relationships between energy consumption and GDP growth and $\mathrm{CO}_{2}$ emission by two distinct models: Model A specifies the relationship between the $\mathrm{CO}_{2}$ emission and energy consumption. Model B specifies energy consumption as a function of a scale variable (like GDP) and other possible exploratory variables.

\section{Model A: The relationships between the environmental destruction and energy consumption}

Dependent Variable: Carbon Dioxide: It is presumed that that the ecological problems is largely driven the by emission of some of the toxic gasses like the Carbon dioxide $\left(\mathrm{CO}_{2}\right)$. Environmental issues are usually measured by emission of some of toxic gases like $\mathrm{CO}_{2}$. Higher levels of $\mathrm{CO}_{2}$ emissions drastically effect the environment. Therefore this paper considers growth rate of $\mathrm{CO}_{2}$ emission on the basis of Kilo Tons, $\mathrm{D}\left(\log \left(\mathrm{CO}_{2}\right)\right)$, as dependent variable.

Independent variable: Energy Consumption: $\mathrm{CO}_{2}$ emission in developing economies such as India and China is due to increasing demand of energy consumption. When energy consumption suddenly increases, $\mathrm{CO}_{2}$ emission increasingly goes up. Therefore this paper considers the logarithm differential of energy consumption on the basis of Kilo Tons for each country as independent variable. Studies have shown that there is a direct relationship between energy consumption and $\mathrm{CO}_{2}$ emission in developing countries. Model A based on fixed effects method is specified as follows:

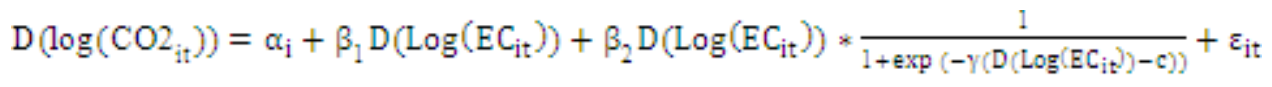

\section{Model B: The relationships between energy consumption and GDP growth}

Dependent Variable: Energy Consumption: There are severe environmental threats in most of the developing economies like India and China because of the growing needs in the form of high energy consumption. It is hypothesized in the earlier argument that as energy consumption increases it leads to more emission of some dangerous toxic gases. we consider log of energy consumption on the basis of Kilo Ton for each country as dependent variable.

Independent Variables: Market Size Growth: energy consumption in developing economies, to a large extent is due to the rapid growth rate of these economies. Higher growth rates put increasing pressure on energy consumption. Therefore GDP is positively related to energy consumption in these developing economies. In this paper, GDP growth rate is considered as substitute variable for market size. Thus, the GDP growth rates are positively associated with the energy consumption in the emerging countries like India, China and Brazil.

Industrialization (IND): It is a known fact that the production and industrial activities involve energy as an essential input. Energy is one of the main resources of industrialization in each country. This economic transition stage results in much higher energy consumption and subsequently the energy needs increase drastically for these economies. This paper considers the share of industrial output to the total GDP as industrialization variable.

Population (POP): As the population grows the needs also increase. The size of population coupled with rise in GDP growth and higher per capita income creates demand for various products and this leads to increase in energy consumption. Both India and China have large number of population residing in rural areas depending more on agriculture. This set of population though are not concerned with the industry, consumes energy in the form of fuel. Thus, in these rural communities though the energy consumption is low but is usually met in the form of fuel and biomass. Therefore, this paper considers population growth rate in India, China and Brazil in order to figure out the influence of population on energy consumption in these countries.

Industrial Export (MEX): Technology advance in international trade has been considered as an advent of rapid economic growth. Industrial manufacturing export in China, India and Brazil is on the rise, therefore 
the manufactured products which are exported to different parts of the world requires higher energy consumption. Suri and Chapman (1998) discussed that Industrial manufacturing export for all developing countries is rising. They also concluded that, the growth rate in this section is higher for developing countries. The other interesting aspect to this argument is that the demand for these products from these economies is increasing at a faster rate and the clients being the developed economies. This is because of the availability of these products at a much cheaper rate because of the low cost resources in developing economies, especially in China, India and Brazil. In this paper Industrial exports share in total exports is used as a proxy for industrial export.

Industrial Imports (MIMP): Industrial imports have an ambiguous effect on energy consumption. Therefore it is important to know industrial imports leads to increase or decrease in energy consumption. Increase in industrial products imports will lead to energy consumption decrease if only the domestic produced goods which are the substitute for industrial imported goods consume higher energy levels. In such case, therefore industrial goods imports will reduce the energy consumption in these countries. Thus, the net effect of increase in manufacturing imports can be either positive or negative for the developing economies.

In the research studied by Chapman (1998), he concluded that for almost all developing countries, industrial imports has a declining trend and even for those economies which their industrial imports have been increasing, the growth rate had been very trivial. About India, the industrial imports' share in total imports has decreased from 1970 (World Development Indicators, 2009). We apply share of manufacturing imports in total Imports as a proxy for industrial import.

Gross Fixed Capital Formation (GFCF): capital Intensive projects especially in infrastructure need high level of energy. In China, in 2006 GFCF had taken about 40 percent of GDP. A great amount of GFCF is related to on infrastructures, creating electricity network and transportation which is remarkably influential on energy consumption in the country. We use gross fixed capital formation as percentage of GDP in model. Model B based on fixed effects method is specified as follows

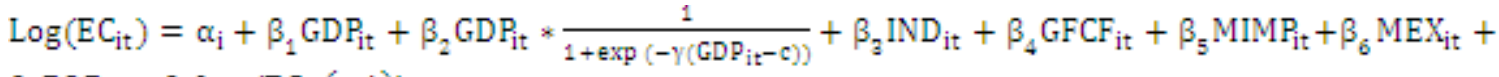

$$
\begin{aligned}
& \beta_{7} P_{\text {Oit }}+\beta_{g} \log \left(E C_{i t}(-1)\right)+\varepsilon_{\text {it }}
\end{aligned}
$$

\section{Results}

The data includes a panel of BRIC countries (Brazil, India and China) over the period 1960-2006. The total observations are 141 which are obtained from WDI (2008) database. We use fixed effects approach to estimates PSTR Models A and B. Before estimating PSTR model, we first should test the linearity hypotheses. If HO hypothesis is rejected, we will estimate the model by method of Non- linear least squares. The linearity hypotheses can be specified as follows:

H0: $\gamma=0$ or $\beta_{2}=0$

In fact, in both cases the test statistics do not have standard distribution, so that with H0 hypothesis, the PSTR model statistics will include nuisance parameters. To overcome the mentioned problem, we use Lagrange Multiplier statistic test (LM). Considering SSR0 as sum of squares of panel residuals under H0 hypothesis (linear panel model with individual effects) and SSR1 as sum of squares of panel residuals under H1 hypothesis or PSTR, the LM statistic will be equal to:

$L M=\frac{\frac{S S R_{0}-S S R_{1}}{K}}{\frac{S N R_{0}}{T N-N-K}}$,

Where $\mathrm{K}, \mathrm{T}$ and $\mathrm{N}$ refer to the number of explanatory variables, time period and the number of cross sections respectively. According to the null hypothesis, the statistics of Lagrange multiplier will be of chisquare distribution with the degree of freedom $\mathrm{K}$ and the corresponding $\mathrm{F}$ statistic will be of the distribution $\mathrm{F}(\mathrm{K}, \mathrm{TN}-\mathrm{N}-\mathrm{K})$. The results of the estimation of the model A has been reported in Table 1 where $\mathrm{CO}_{2}$ emission logarithm differential, $\mathrm{D}\left(\log \left(\mathrm{CO}_{2}\right)\right)$, is considered as dependent variable, representing the environmental destruction. The optimal lag length according to statistical tests and model selection criteria has been selected zero. As indicated, the coefficient $\beta_{2}$ is insignificant in PSTR model A, implying that the relationship between growth rates of $\mathrm{CO}_{2}$ emission and GDP is linear. Hence, the linearity test, on the basis of LM statistic is done. The value of LM statistic is 0.407 which is much 
lower than critical values (with the freedom degrees of 3 and 93) in conventional significant levels. So, the null hypothesis based upon the linear model is not rejected.

The results of estimation of the linear relationship between energy consumption and $\mathrm{CO}_{2}$ emission (in terms of growth rates) are reported in the third column of Table 1. The coefficient of energy consumption equals 1.91and the value of DW statistic is 2.03 which is the indicator of lack of autocorrelation in the model. The short run elasticity of the impact of energy consumption on $\mathrm{CO}_{2}$ emission is above unity (1.91), indicating that a $10 \%$ increase in energy consumption increases emissions by $19.1 \%$. So, economic growth progressively raises energy consumption.

Table1: The results of the estimation of the model A in forms PSTR and linear.

\begin{tabular}{lll}
\hline coefficient & model PSTR & Linear model \\
\hline$\beta_{1}$ & $* 1.61$ & $* 1.91$ \\
& $(0.474)$ & $(0.1)$ \\
$\beta_{2}$ & -0.49 & \\
& $(0.536)$ & $\cdots$ \\
$\mathrm{C}$ & 0.001 & $\ldots$ \\
$\gamma$ & 24.1 & $\ldots$ \\
$\mathrm{R}^{2}$ & 0.588 & 0.584 \\
LM Statistics & 0.407 & \\
SSR & 0.076 & 0.077 \\
DW & 2.07 & 2.03 \\
\hline
\end{tabular}

Note: standard errors are reported as $0 .{ }^{*}$ indicate rejection of the null at the $1 \%$ significance level.

In table 2, the relationships between the energy consumption and GDP growth rate along with another independent variables including market size growth, industrialization, gross fixed capital formation, industrial imports, industrial exports and population has been estimated. Dependent variable is logarithm of energy consumption. Because of residuals autocorrelation in static model, the logarithm of energy consumption variable with a lag is entered to the right of the equation, as an independent variable. The linearity test based on LM statistic rejects the null, indicating that there is strong evidence of nonlinearity. Moreover, the threshold amount is estimated 8.3. Both estimates of $\beta_{1}$ and $\beta_{2}$ is positive and significant, implying that economic growth progressively increases energy consumption. As it is seen, the estimates for industrial imports variables and population growth rate are not significant. All of the other estimates are significant in high confidence levels. The industrialization coefficient is negative and marginally significant. Indeed industrial output growth above overall economic growth has restricted energy consumption in these countries. Increasing gross fixed capital formation also, energy consumption increases. As expected, higher level of investments in BRIC economies significantly affects the energy consumption.

Table2: The results of the estimation of $B$ model

\begin{tabular}{llllll}
\hline Coefficients & Estimates & Coefficients & Estimates & Coefficients & Estimates \\
\hline$\beta_{1}$ & $0.002^{* *}$ & $\beta_{5}$ & -0.0002 & $\mathrm{c}$ & 8.3 \\
& $(0.02)$ & & $(0.43)$ & & \\
$\beta_{2}$ & $0.002^{* * *}$ & $\beta_{6}$ & $0.0005^{* *}$ & $\gamma$ & 2.15 \\
$\beta_{3}$ & $(0.001)$ & & $(0.07)$ & & \\
$\beta_{4}$ & $-0.001^{*}$ & $\beta_{7}$ & -0.016 & & \\
LM Statistics= $19.54^{* * *}$ & $(0.09)$ & $(0.23)$ & & \\
Adjusted $\mathrm{R}^{2}=0.99, \mathrm{R}^{2}=0.99, \mathrm{SSR}=0.045$ & & $0.96^{* * *}$ & & \\
\hline
\end{tabular}

Note: p-values are reported in (). ${ }^{* *},{ }^{* *}$ and ${ }^{*}$ indicate rejection of the null at the $1 \%, 5 \%$ and $10 \%$ significance levels respectively. 
Our empirical results demonstrate that there is a strongly non-linear link between energy consumption and GDP growth. As GDP growth rises, energy consumption rapidly increases first, and after the level of GDP growth exceeds approximately 8.3, its increasing rate turns to be slow. Evidence of a U-shaped relationship between energy consumption and GDP growth is supported, and the threshold value is approximately 8.3 .

\section{Conclusion}

This study applies a non-linear model, i.e. the recently developed panel smooth transition regression (PSTR) model, and takes into account the potential endogeneity biases to investigate the relationships between the energy consumption, GDP growth and $\mathrm{CO}_{2}$ emission for BRIC countries over the period 1960 -2006. The PSTR model can endogenously determine whether the energy consumption function is nonlinear and allows for a continuum of an intermediate regime among different extremes. When growth rate increases remarkably, there will be an increasing pressure on resources. Therefore the demand for expert labor force, capital and equipment increases and more raw materials and energy is consumed. In this paper, we examine the nonlinear relationships between energy consumption, GDP growth rate and $\mathrm{CO}_{2}$ emission for three countries; India, China and Brazil during the period 1960-2006.

While modeling the relationships between the energy consumption and GDP growth rate, the existence of cross-section heterogeneity and instability in the energy demand equation leads to bias in the result. If these two problems are ignored in econometric analysis, the results of estimation may be bias. To solving this problem, we use smooth transition regression model (PSTR) to capture the heterogeneities and nonlinearities. In this method, changing the parameters among countries and also during the time is modeled continuously. Thus, this approach is proper for removing the heterogeneity among the countries and variability of the relationship between GDP and energy consumption over time. The results indicate energy consumption increasingly leads to environmental destruction in these countries. Moreover, the higher energy consumption is a consequence of rapid economic growth and international trade related to industrial goods. As these countries enjoy higher economic growth rates, the higher would be the energy consumption levels leading to environmental imbalances.

\section{References}

Agras, J. \& Chapman, D. (1999). A dynamic approach to the Environmental Kuznets Curve hypothesis. Energy Economics, 28, 267-277.

Azomahu, T. \& Van Phu, N. (2001). Economic growth and $\mathrm{CO}_{2}$ emission: a nonparametric approach. BETA working paper, 2001-01.

Baiocchi, G. \& Di Falco, S. (2001). Investigating the Shape of the EKC: a nonparametric Approach. Nota di Lavoro 66.01, Fondazione Eni Enrico Mattei.

Bacon, D. W. \& Watts, D. G. (1971). Estimating the transition between two intersecting Straight lines. Biometrika, 58, 19-52.

Destais, G., Fouquau, J. \& Hurlin, C. (2009). Energy Demand Models: A Threshold Panel Specification of the Kuznets Curve. Université De Grenoble.

Dinda, S. (2004). Environmental Kuznets curve hypothesis: a survey. Ecological Economics, 49, 431-455.

Cole, M. A., Rayner, A. J. \& Bates J. M. (1997). The environmental Kuznets curves: an empirical analysis. Environment and Development Economics, 2, 401- 416.

Colletaz, G. \& Hurlin, C. (2006). Threshold effects in the public capital productivity: an international panel smooth transition approach. University of Orleans, Working paper.

Copeland, B. R. \& Taylor, M. S. (2004). Trade, growth and the environment. Journal of Economic Literature, 42, 7-71.

Friedl, B. \& Getzner, M. (2003). Determinants of $\mathrm{CO}_{2}$ emission in a small open economy. Ecological economics. 45, 133-148.

Fok, D., van Dijk, D. \& Franses, P. (2004). A multi-level panel STAR model for US manufacturing sectors. Working Paper University of Rotterdam.

Fouquau, J., Hurlin, C. \& Rabaud, I. (2008). The Feldstein-Horioka puzzle: a panel smooth transition regression approach. Economic modeling, 25, 284-299.

Galeotti, M., Lanza, A. \& Pauli, F. (2006). Reassessing the environmental Kuznets curves for $\mathrm{CO}_{2}$ emission: A robustness exercise. Ecological Economics, 57,152-163.

Granger, C. \& Terasvirta, T. (1993). Modelling non linear economic relationships, Oxford University press. 
Grossman, G. \& Krueger, A. (1992). Environmental impacts of a North American free trade agreement. Discussion Papers in Economics c158, Woodrow Wilson School of Public and International Affairs, Princeton.

Grossman, G. \& Krueger, A. (1995). Economic growth and the environment. Q. J. Econ, 110 (2), 352-377.

González, A., Teräsvirta, T. \& van Dijk, D. (2005).Panel smooth transition regression model. Working Paper Series in Economics and Finance, 604.

Heerink, N., Mulatu, A. \& Bullet, F. (2001). Income inequality and the environment: aggregation bias in Environmental Kuznets Curves. Ecological Economics, 38 (3), 359-367.

Hansen, P. \& King, A. (1996). The determinants of health care expenditure: a cointegration approach. Journal of Health Economics, 15 (1), 127-137.

Hill, R. J. \& Magnani, E. (2002).An exploration of the conceptual and empirical basis of the environmental Kuznets curve. Australian Economic papers, 41, 239-254.

Holtz - Eakin, D. \& Selden, T. M. (1995). Stoking the fires? $\mathrm{CO}_{2}$ emissions and economic growth. Journal of Public Economics, 57 (1), 85-101.

Hsiao, C. (2003). Analysis of panel data, publication by the press syndicate of the University of Cambridge, second edition.

Huang, B. N., Huang, M. J. \& Yang, C. W. (2008). Causal relationship between energy consumption and GDP growth revisited: a dynamic panel data approach. Ecological Economics, forthcoming.

Juan, P., Tamazian, A. \& Chaitanya, K. (2008). Rapid economic growth at the cost of environment degradation? Panel data evidence from BRIC economic. Working paper.

Lantz, V., Feng, Q., (2006). Assessing income, population, and technology impacts on CO2 emissions in Canada: where's the EKC? Ecological Economics, 57,229-238.

Lee, C. C. \& Chang, C. P. (2007a). Energy consumption and GDP revisited: a panel analysis of developed and developing countries. Energy Economics, 29 (6), 1206-1223.

Lee, C. C. \& Chang, C. P. (2007b). The impact of energy consumption on economic growth: evidence from linear and nonlinear models in Taiwan. Energy, 32, 2282-2294.

Lindmark, M. (2002). An EKC-pattern in historical perspective: carbon dioxide emissions, technology, fuel prices and growth in Sweden 1870-1997. Ecological Economics, 42, 333-347.

Martinez-Zarzoso, I., Bengochea-Morancho, A. \& Hihon-Tamarit, F. (2002). Testing for Environmental Kuznets Curves: empirical evidence from pooled mean estimates. Paper under revision in Environmental and Resource Economics.

Martinez - Zarzoso, I. \& Bengochea-Morancho, A. (2003) .Testing for an Environmental Kuznets Curve in Latin-American countries. Revista de Ana'lisis Econo'mico, 18(1), 3-26.

Mielnik, O. \& Goldenberg, J. (1999).The evaluation of the carbonization index in developing countries. Energy Policy, 27,307-308.

Moon, Y. S. \& Sonn, Y. H. (1996). Productive energy consumption and economic growth: an endogenous growth model and its empirical application. Resource and Energy Economics, 18, 189-200.

Neumayer, E. (2002).Can natural factors explain any cross-country difference in carbon dioxide emission? Energy Policy, 30, 7-12.

Opschoor, J. B. (1997). Industrial metabolism, economic growth and institutional change, In Redclift, M., Woodgate, G (eds.): The International Handbook of Environmental Sociology. Edward Elgar, Cheltenham.

Pesaran, H. M. \& Smith, R. (1995). Estimating long-run relationships from dynamic heterogenous panels. Journal of Econometrics, 68, 79-113.

Roca, J. \& Alcantara, V. (2001).Energy intensity, $\mathrm{CO}_{2}$ emission and the environmental Kuznets curve, The Spanish case. Energy Policy, 29, 553-556.

Sengupta, R. (1996). $\mathrm{CO}_{2}$ Emission-Income relationship ship: policy approach for climate control. Pacific and Asian Journal of Energy, 7 (2), 207-229.

Selden, T. M. \& Song, D. (1994). Environmental quality and development: is there a Kuznets Curve for air pollution? J. Environ. Econ. Manage, 27 (2), 147-162.

Stern, D. I. (2004). The rise and fall of the environmental Kuznets curve. World Development 32, 14191439.

Shafik, N. \& Bandyopadhyay, S. (1992).Economic growth and environmental quality: time-series and cross-country evidence. Background Paper for World Development Report 1992, The World Bank, Washington, D.C.

Soytaş, U., Sari, R. \& Bradley, T. E. (2007). Energy consumption, income, and carbon emissions in the United States. Ecological Economics, 62,482-489. 
Suri, V. \& Chapman, D. (1998). Economic growth, trade and energy: implications for the Environmental Kuznets Curve. Ecological Economics, Special Issue on the Environmental Kuznets Curve, 25 (1998) 195-208.

Taskin, F. \& Zaim, O. (2000). Searching for a Kuznets curve in environmental efficiency using Kernel estimation, Economics Letters, 68, 217-223.

Tucker, M. (1995). Carbon dioxide emissions and global GDP. Ecol. Econ, 15 (3), 215-223.

World Bank. (2005). World Development Report. Washington: World Bank Press. 